\title{
Maternal-Fetal Prognosis of Delivery in the Presentation of the Seat at the Kayes Hospital (Mali)
}

\author{
Mahamadou Diassana1, Ballan Macalou1, Sitapha Dembele1, A. Sidibe², A. Hamido², D. Konate², \\ Soumana Oumar Traore ${ }^{3}$, Mamadou Sima4, Cheickna Sylla5, Amadou Bocoum5, Seydou Fane5, \\ Soumaila Traore 6
}

\author{
${ }^{1}$ Obstetrics and Gynecology Department at Fousseyni DAOU Hospital, Kayes, Mali \\ ${ }^{2}$ Kayes Reference Health Centre, Kayes, Mali \\ ${ }^{3}$ Reference Health Centre in Bamako Commune V, Bamako, Mali \\ ${ }^{4}$ Department of Gynecology and Obstetrics at the G-Spot University Hospital, Bamako, Mali \\ ${ }^{5}$ Department of Obstetrics and Gynecology at GABRIEL TOURE University Hospital, Bamako, Mali \\ ${ }^{6}$ Department of Obstetrics and Gynecology at SIKASSO Regional Hospital, Sikasso, Mali \\ Email: mahamadoudiassana@gmail.com
}

How to cite this paper: Diassana, M., Macalou, B., Dembele, S., Sidibe, A., Hamido, A., Konate, D., Traore, S.O., Sima, M., Sylla, C., Bocoum, A., Fane, S. and Traore, S. (2021) Maternal-Fetal Prognosis of Delivery in the Presentation of the Seat at the Kayes Hospital (Mali)e. Open Journal of Obstetrics and Gynecology, 11, 578-590.

https://doi.org/10.4236/ojog.2021.115054

Received: April 5, 2021

Accepted: May 17, 2021

Published: May 20, 2021

Copyright $\odot 2021$ by author(s) and Scientific Research Publishing Inc. This work is licensed under the Creative Commons Attribution International License (CC BY 4.0).

http://creativecommons.org/licenses/by/4.0/ (c) (i) Open Access

\begin{abstract}
Objective: The purpose of this study was to assess the risk factors associated with seat presentation and to determine the maternal-fetal prognosis of delivery in the presentation of the seat. Materials and methods: This was a descriptive, cross-sectional and analytical case-control study with prospective data collection, from January 1, 2018 to December 31, 2019, a 12-month period at Kayes Hospital, Mali. Results: During our study period we recorded 3820 deliveries, including 120 breos; a frequency of 3.14\% of all deliveries. The 20 - 35 age group was the most represented in cases $61.7 \%$. Of the cases $66.7 \%(n-80)$ were out of school, we note $75.8 \%$ (n-182) of out-of-school controls. Primiparaes were the majority among cases $39.2 \%(n-47)$, as were $39.1 \%$ of the controls ( $\mathrm{n}-118)$. The cases had a history of caesarean section at $15 \%(n-18) ; 13,3 \%$ (n-32). The most common mode of presentation was the $70 \%$ decomplete seat. It was mainly the anterior left sacro iliac variety (85.8\%). The low pathway was preferred during these deliveries to $70 \%$ against $30 \%$ of caesarean section of which $28.3 \%$ of cases were carried out in an emergency. Several factors such as delivery pathway, mode of presentation, length of expulsion and obstetric manoeuvres used influenced fetal prognosis. Fetal complications were dominated by acute fetal suffering (15.8\%), followed by dislocation of the shoulder $(0.8 \%)$. The most common morbid maternal complications were soft part tears (15 cases or $12.5 \%)$ and parietal suppuration (1 case or $0.8 \%$ ). We did not record any maternal deaths.
\end{abstract}


Conclusion: Our results confirm that childbirth is a risky delivery, and must require careful selection of eligible cases and rigorous management of labour with trained teams. In these circumstances, it seems totally abusive to advocate as a single mode of delivery caesarean section in all presentations of the chair in the primigestes.

\section{Keywords}

Siege Delivery, Obstetric Prognosis

\section{Introduction}

Seat presentation is a longitudinal presentation where the pelvic end of the fetus first appears in the upper strait area. This is the most common irregular presentation. The overall incidence of breo-seat deliveries worldwide ranges from 3\% to $4.2 \%$ [1]. In Africa, it ranges from $1.52 \%$ to $5.4 \%$. In Mali, Koné M. [2] had found in two years a frequency of $2.74 \%$ of all deliveries at the Gabriel Touré University Hospital. It is a high-risk birth of mortality and fetal-maternal morbidity because of its potentially "dystoctic" nature. Therefore, a situation worries the obstetricalteame around the world [1]. The mode of delivery in the presentation of the term seat remains at the origin of much passionate debate around the world. Vaginal delivery in the event of a brecover presentation would be associated with an increased risk of perinatal mortality. As early as 1951 WRIGHT advocated routine caesarean section in order to reduce the perinatal morbidity and mortality rate 4 - 6 times higher than the presentation of the summit [3]. This attitude was very controversial at the time given the risk associated with the excess mortality and morbidity of caesarean section. The conditions of delivery are much better at present, yet the abundance of literature on perinatal prognosis still revives debates between proponents of routine caesarean section and supporters of the lower track in the event of siege presentation [4] [5]. This discrepancy prevents the definition of a standard therapeutic attitude towards childbirth in the presentation of the seat. In developing countries, in addition to the prognosis problem associated with childbirth, the presentation of the siege also poses the problem of diagnosis, monitoring of pregnancy given the lack of health infrastructure and qualified medical personnel [2]. The lack of previous studies on this type of birth in our department motivated the initiation of this work.

\section{Objective}

The goal was to assess the risk factors associated with seat presentation and to determine the maternal-fetal prognosis of delivery in presentation of the seat.

\section{Materials and Methods}

This was a descriptive, cross-sectional and analytical case-control study with a prospective collection of data, ranging from January 1, 2018 to December 31, 
2019, a 12-month period at Kayes Hospital, Mali. Inclusion criteria: were included in our study: all cases and controls recorded during the study period. Cases, all pregnant and/or parturients admitted to the service for obstetric care on a pregnancy greater than or equal to 28 weeks of amenorrhea (SA) with fetuses presenting the seat. Witnesses, all pregnant and/or parturients admitted to the service for obstetrical care on a pregnancy greater than or equal to $28 \mathrm{SA}$ with fetuses in presentation of the summit. For each case of brecge delivery, the following two summit presentation deliveries were taken as witnesses. The exclusion criteria: were excluded from this work: any other mode of presentation: forehead, face, transverse; fetal malformations incompatible with life; stillborn fetuses macerated. The data collection was done by an individual survey sheet for each patient. The data sources were made up of the CPN Notebooks, patient records, patient examination, the operating report registry, the delivery register. The data entry was done on Microsoft Word 10 and analyzed on Microsoft Excel 10, IBM SPSS 20 software. The anonymity and confidentiality of those involved in the study were respected. The limitations of this work were among other things: the absence of third trimester ultrasound and radiopelvimetry in most of our parturients; the lack of specific means of monitoring labour (cardiotocograph, $\mathrm{PH}$ metrics).

\section{Results}

\subsection{Epidemiological Aspects}

During our study period, we recorded 120 breest deliveries out of a total of 3820 deliveries, a frequency of $3.14 \%$. The 20 - 35 age group was the most represented at $61.7 \%$ with anaverage age of 25 years and extremes ranging from 14 to 45 years for cases versus an average age of 26 years and extremes ranging from 15 to 44 years for controls. Of the cases $66.7 \%$ of the parturients were out of school compared to $75.8 \%$ of out-of-school controls. Housewives accounted for $84.2 \%$ of the number of cases compared to $87.9 \%$ of witnesses. On the other hand, $2.5 \%$ were civil servants compared to $0 \%$ of witnesses. These epidemiological aspects are summarized in Table 1 and Figure 1.

\subsection{Clinical Aspects}

Reference/Evacuation: parmi cases $79.20 \%$ of parturients were admitted directly against $20.80 \%$ reference/Evacuation. Primipares accounted for $39.2 \%$ of the workforce among cases compared to $39.1 \%$ for witnesses. (No.118). The history of caesarean section was noted in $15 \%$ of the parturients among the cases compared to $13.3 \%$ among the controls. Prenatal consultations were of good quality in $4.1 \%$ versus $5 \%$ among controls. They were of poor quality in $25 \%$ against $34.2 \%$ among witnesses. The associated risk actors $\mathrm{f}$ were uterine myoma in 1.7\%; uterine malformation in 4.2\%; hydramnios 2.5\%; scarred uterus in $11.7 \%$; géméllity $32.4 \%$. Birth labour abnormalities were dominated by dynamic dystocies in $15 \%$ in cases versus $6.2 \%$ among controls; mechanical dystocies 
Table 1. Epidemiological aspects.

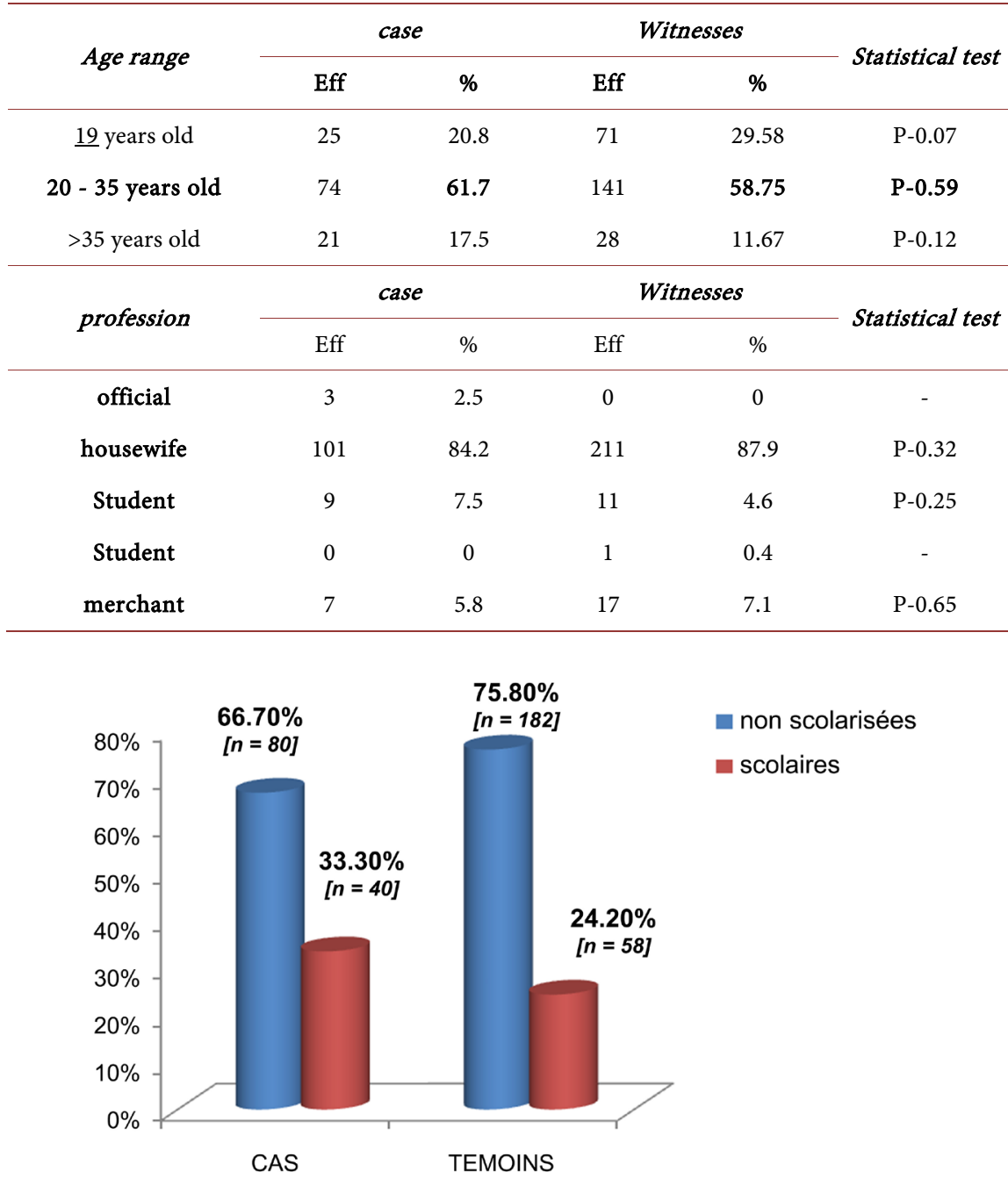

Figure 1. Distribution of women by level of education. Of the cases, 66.70 per cent $(\mathrm{N}-80)$ were out of school and 33.30 per cent $(\mathrm{N}-40)$ were in school; Of the controls, 75.80 per cent $(\mathrm{N}-182)$ were out of school and 24.20 per cent $(\mathrm{N}-8)$ were in school.

were noted in $11.5 \%$ versus $5.4 \%$ among controls; hemorrhage in $3.3 \%$ versus $1.7 \%$ of controls; cord procidence in $1.7 \%$. The delivery pathway among the cases was the caesarean section at $30 \%$ and the low pathway at $70 \%$; that of the controls was the caesarean section at $7.1 \%$ and the lower pathway at $92.9 \%$. The duration of the labour was 12 hours in $81.7 \%$ in the series of cases and $97.5 \%$ in the controls. The length of deportation was 45 minutes in $90 \%$ in the series of cases and $93.75 \%$ in the controls. Episiotomy was performed in $70 \%$ of cases and $6.7 \%$ of controls. In cases $36 \%$ of deliveries took place without any obstetric maneuvering. Obstetrical work. BRACHT was used in 60\% of cases, MAURICEAU in $9.2 \%$ of cases and LOVSET in $0.8 \%$ of cases. The indications of caesarean section: cesarean sections were performed before labour and during labour. Before labour, the presentation of the seat in a primipara was noted in 1cas and 7 cas during labour. The fetal-pelvic disproportion was noted in 2 cas. 14 cas of 
cicatricial uterus were noted. Stationary dilation was noted in 4 cas; only one case of fetal suffering was reported; cord procidence 4 cas; pelvis abnormalities 3 cas condylome 1 cas. Macrosomy involved 6 infants, or $5 \%$ of cases. These clinical aspects presented in Figure 2 and Tables 2-4.

Table 2. Clinical aspects (Risk Factors for Head Office Presentation) 2018-2019 at Kayes Hospital, Mali.

\begin{tabular}{|c|c|c|c|c|c|}
\hline \multirow{2}{*}{ parity } & \multicolumn{2}{|c|}{ case } & \multicolumn{2}{|c|}{ Witnesses } & \multirow{2}{*}{ Statistical test } \\
\hline & Eff & $\%$ & Eff & $\%$ & \\
\hline Primipare & 47 & 39.2 & 118 & 49.1 & P- -0.07 \\
\hline Paucipare & 37 & 30.8 & 63 & 26.3 & P-0.36 \\
\hline Multipare & 17 & 14.2 & 35 & 14.6 & P-0.91 \\
\hline Large multipare & 19 & 15.8 & 24 & 10 & P-0.10 \\
\hline \multicolumn{6}{|l|}{ Surgical anecerties } \\
\hline caesarean section & 18 & 15 & 32 & 13.3 & P-0.66 \\
\hline Myomectomy & 2 & 1.7 & 1 & 0.4 & P-0.53 \\
\hline Uterine plastia & 0 & 0 & 1 & 0.4 & - \\
\hline none & 100 & 83.3 & 206 & 85.9 & P-0.53 \\
\hline $\begin{array}{c}\text { Quality Prenatal } \\
\text { Consultation (NPC) }\end{array}$ & & & & & Statistical test \\
\hline good & 5 & 4.1 & 12 & 5 & P-0.72 \\
\hline Average & 74 & 61.7 & 118 & 49.2 & P-0.02 \\
\hline bad & 30 & 25 & 82 & 34.2 & P-0.07 \\
\hline Not done & 11 & 9.2 & 28 & 11.6 & P-0.47 \\
\hline $\begin{array}{c}\text { Risk factors associated } \\
\text { with }\end{array}$ & & & & & Statistical test \\
\hline Uterine Myoma & & & & & - \\
\hline Uterine malformation & 5 & 4.2 & 1 & 0.4 & P-0.02 \\
\hline Hydramnios & 3 & 2.5 & 0 & 0 & - \\
\hline Scarred uterus & 14 & 11.7 & 3 & 1.3 & P- 0.73 \\
\hline Gemini & 39 & 32.4 & 0 & 0 & - \\
\hline None & 57 & 47.5 & 236 & 98.3 & P-lt;0.05 \\
\hline
\end{tabular}

Table 3. Clinical aspects.

\begin{tabular}{cccccc}
\hline \multirow{2}{*}{ Work anomaly } & \multicolumn{3}{c}{ case } & \multicolumn{4}{c}{ Witnesses } & \multirow{2}{*}{ Statistical test } \\
\cline { 2 - 5 } & Eff & $\%$ & Eff & $\%$ & \\
\hline Dynamic dystocia & 18 & 15 & 15 & 6.2 & P-0.006 \\
Mechanical dystocia & 14 & 11.7 & 13 & 5.4 & P-0.03 \\
haemorrhage & 4 & 3.3 & 4 & 1.7 & P-0.52 \\
\hline
\end{tabular}




\section{Continued}

\begin{tabular}{|c|c|c|c|c|c|}
\hline Cord procidence & 2 & 1.7 & 0 & 0 & - \\
\hline No & 82 & 68.3 & 208 & 86.7 & - \\
\hline \multicolumn{6}{|l|}{ Obstetric maneuvers } \\
\hline Bracht & \multicolumn{2}{|c|}{72} & \multicolumn{2}{|c|}{60} & \\
\hline Mauritius & \multicolumn{2}{|c|}{11} & \multicolumn{2}{|c|}{9.2} & \\
\hline Lovset & \multicolumn{2}{|c|}{1} & \multicolumn{2}{|c|}{0.8} & \\
\hline No & \multicolumn{2}{|c|}{36} & \multicolumn{2}{|c|}{30} & \\
\hline \multirow{2}{*}{ Birth weight } & \multicolumn{2}{|c|}{ Case } & \multicolumn{2}{|c|}{ Witnesses } & \multirow{2}{*}{ Statistical test } \\
\hline & Eff & $\%$ & Eff & $\%$ & \\
\hline $2500 \mathrm{~g}$ & 19 & 15.8 & 3 & 1.3 & $\mathrm{P}$ and lt; 0.05 \\
\hline $2500 \mathrm{~g}-3500 \mathrm{~g}$ & 86 & 71.7 & 224 & 93.3 & $\mathrm{P}$ and lt; 0.05 \\
\hline $3500 \mathrm{~g}-4000 \mathrm{~g}$ & 9 & 7.5 & 11 & 4.6 & P- -0.25 \\
\hline $4000 \mathrm{~g}$ & 6 & 5 & 2 & 0.8 & $\mathrm{P}-0.03$ \\
\hline
\end{tabular}

Table 4. Clinical aspects.

\begin{tabular}{|c|c|c|c|c|c|}
\hline \multirow{2}{*}{ Delivery path } & \multicolumn{2}{|c|}{ case } & \multicolumn{2}{|c|}{ Witnesses } & \multirow[t]{2}{*}{ Stastitic testing } \\
\hline & Effectif & $\%$ & Effectif & $\%$ & \\
\hline caesarean section & 36 & 30 & 17 & 7.1 & \\
\hline low lane & 84 & 70 & 223 & 92.9 & \\
\hline \multicolumn{6}{|l|}{ Working time } \\
\hline $12 \mathrm{H}$ & 98 & 81.7 & 234 & 97.5 & $\mathrm{P}$ and lt; 0.05 \\
\hline $12 \mathrm{H}$ & 22 & 18.3 & 6 & 2.5 & $\mathrm{P}$ and lt; 0.05 \\
\hline \multicolumn{6}{|l|}{ Length of deportation } \\
\hline 45 minutes & 108 & 90 & 225 & 93.75 & \\
\hline 45 minutes & 12 & 10 & 15 & 6.25 & \\
\hline \multicolumn{6}{|l|}{ Episiotomy } \\
\hline Yes & 84 & 70 & 16 & 6.7 & \\
\hline No & 36 & 30 & 224 & 93.3 & \\
\hline Indications of caesarean section & $\begin{array}{c}\text { Before the } \\
\text { birthing } \\
\text { labour }\end{array}$ & $\begin{array}{c}\text { During the } \\
\text { labour of } \\
\text { delivery }\end{array}$ & & & \\
\hline Introducing the seat at primipare & 1 & 7 & & & \\
\hline Fetal-pelvic disproportion & 0 & 2 & & & \\
\hline Scarred uterus & 2 & 12 & & & \\
\hline Stationary dilation & 0 & 4 & & & \\
\hline Acute fetal suffering & 0 & 1 & & & \\
\hline Cord procidence & 0 & 4 & & & \\
\hline pelvis abnormalities & 1 & 2 & & & \\
\hline
\end{tabular}




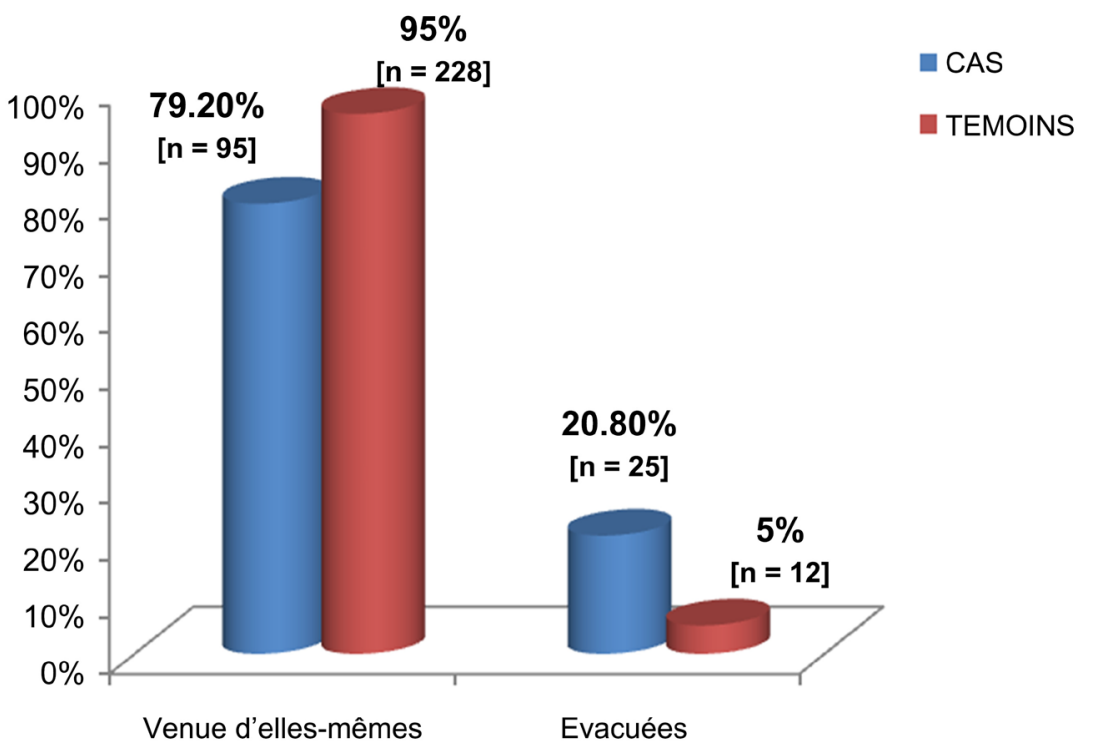

Figure 2. Distribution of women by admission, $\mathrm{Chi}^{2}-21.7$; dll 1; p-lt; 0.05 . Of the cases $79.20 \%(\mathrm{~N}-95)$ had come on their own and $20.80 \%$ (N-25) were evacuated; Of the controls $95 \%(\mathrm{~N}-228)$ had come on their own and $5 \%(\mathrm{~N}-12)$ were evacuated.

\subsection{Maternal-Fetal Prognosis}

Maternal complications were dominated by vulvo-vaginal tears $12.5 \%$, parietal Suppuration 0.8\%; we recorded no maternal complications in controls, nor any maternal deaths in the study. Neonatal complications: dislocating the shoulder 1 cas or $\mathbf{0 . 8 \%} .95 .8 \%$ of the newborns in our series were born alive however $4.2 \%$ died. Thematernal-fetal prognosis is summarized in Table 5.

\section{Analytical results (Table 6).}

\section{Discussion}

\subsection{Epidemiological Aspects}

In the literature, authors report variable frequency rates. During the study period, we collected 120 breest deliveries out of a total of 3820 deliveries, representing a frequency of $3.14 \%$. Table 7 presents data on the frequency of birth by the seat by the authors.

The frequency of siege deliveries varies from country to country. Our high rate of seat presentation could be explained on the one hand: the fact that we have included multiple pregnancies and preterm births that are frequently associated with the presentation of the seat; and on the other hand by the fact that our service is the last resort for the management of obstetric emergencies in the referral/evacuation system in the Kayes area.

Age: We did not find a statistically significant difference between the average age of our cases 25 years and that of their witnesses P-0.05. This result is similar to those of Dicko B. [9], Koné M. [2] in Mali, Farsi I F. [10] in Senegal, Macombou P. [6] in Congo, Erkaya S. [11] in Turkey, and Rosenau L. [12] in France, which reported an average age of 24, 26 years, 27 years, 29 years, 25 years and 27 
Table 5. The maternal-fetal prognosis.

\begin{tabular}{|c|c|c|c|c|c|}
\hline \multirow{2}{*}{ Maternal complications } & \multicolumn{2}{|c|}{ Case } & \multicolumn{2}{|c|}{ Witnesses } & \\
\hline & Eff & $\%$ & Eff & $\%$ & \\
\hline Vulvo-vaginal tear & 15 & 12.5 & 0 & 0 & \\
\hline Parietal suppuration & 1 & 0.8 & 0 & 0 & \\
\hline Death & 0 & 0 & 0 & 0 & \\
\hline No & 104 & 86.6 & 240 & 100 & \\
\hline \multirow{2}{*}{$\begin{array}{l}\text { Fetal and neonatal } \\
\text { complications }\end{array}$} & \multicolumn{2}{|c|}{ Case } & \multicolumn{2}{|c|}{ Witnesses } & \multirow{2}{*}{ Statistical test } \\
\hline & Eff & $\%$ & Eff & $\%$ & \\
\hline SFA & 19 & 15.8 & 1 & 0.4 & $\mathrm{P}$ and lt; 0.05 \\
\hline fracture & 0 & 0 & 0 & 0 & - \\
\hline Brachial plexus paralysis & 0 & 0 & 0 & 0 & - \\
\hline Shoulder luxation & 1 & 0.8 & 0 & 0 & - \\
\hline No & 100 & 83.4 & 239 & 99.6 & $\mathrm{P}$ and lt; 0.05 \\
\hline \multirow{2}{*}{ Newborn status } & \multicolumn{2}{|c|}{ Case } & \multicolumn{2}{|c|}{ Witnesses } & Ctutivitu t to \\
\hline & Eff & $\%$ & Eff & $\%$ & 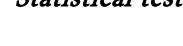 \\
\hline alive & 115 & 95.8 & 240 & 100 & P-0.06 \\
\hline deceased & 5 & 4.2 & 0 & 0 & - \\
\hline
\end{tabular}

Table 6. Analytical results.

\begin{tabular}{|c|c|c|c|c|c|c|c|c|c|}
\hline \multirow{4}{*}{ parity } & \multicolumn{8}{|c|}{ Delivery lane } & \multirow{4}{*}{-Statistical test } \\
\hline & \multicolumn{4}{|c|}{ caesarean section } & \multicolumn{4}{|c|}{ Low track } & \\
\hline & \multicolumn{2}{|c|}{ case } & \multicolumn{2}{|c|}{ Witnesses } & \multicolumn{2}{|c|}{ case } & \multicolumn{2}{|c|}{ Witnesses } & \\
\hline & Eff & $\%$ & Eff & $\%$ & Eff & $\%$ & Eff & $\%$ & \\
\hline Primipare & 25 & 69.4 & 9 & 53 & 22 & 26.2 & 109 & 48.9 & P-lt; 0.05 \\
\hline Paucipare & 8 & 22.2 & 4 & 23.5 & 29 & 34.5 & 59 & 26.5 & $\mathrm{P}-0.4$ \\
\hline Multipare & 1 & 2.8 & 1 & 5.9 & 16 & 19.1 & 34 & 15.2 & P-0.08 \\
\hline \multirow[t]{2}{*}{ Large multipare } & 2 & 5.6 & 3 & 17.6 & 17 & 20.2 & 21 & 9.4 & P-0.03 \\
\hline & \multicolumn{8}{|c|}{ Pregnancy monitoring } & \\
\hline \multirow{3}{*}{$\begin{array}{c}\text { Apgar score in } \\
\text { the }^{1 s t} \text { minute }\end{array}$} & \multicolumn{4}{|c|}{ Yes } & \multicolumn{4}{|c|}{ No } & \\
\hline & \multicolumn{2}{|c|}{ case } & \multicolumn{2}{|c|}{ Witnesses } & \multicolumn{2}{|c|}{ case } & \multicolumn{2}{|c|}{ Witnesses } & \\
\hline & Eff & $\%$ & Eff & $\%$ & Eff & $\%$ & Eff & $\%$ & \\
\hline 0 & 0 & 0 & 0 & 0 & 0 & 0 & 0 & 0 & \\
\hline $1-3$ & 4 & 3.7 & 1 & 0.5 & 0 & 0 & 0 & 0 & \\
\hline $4-6$ & 18 & 16.5 & 3 & 1.4 & 4 & 36.4 & 0 & 0 & \\
\hline 7 & 87 & 79.8 & 208 & 98.1 & 7 & 63.6 & 28 & 100 & \\
\hline \multirow{3}{*}{$\begin{array}{c}\text { Apgar score in } \\
\text { the }^{1 s t} \text { minute }\end{array}$} & \multicolumn{8}{|c|}{ Obstetric maneuvers } & \\
\hline & \multicolumn{3}{|c|}{ Bracht } & \multicolumn{2}{|c|}{ Mauritius } & \multicolumn{3}{|c|}{ Lovset } & \\
\hline & Eff & $\%$ & & Eff & $\%$ & Ef & & $\%$ & \\
\hline 0 & 0 & 0 & & 0 & 0 & 0 & & 0 & \\
\hline $1-3$ & 1 & 1. & & 2 & 18.2 & 0 & & 0 & \\
\hline $4-6$ & 8 & 11. & & 8 & 72.7 & 1 & & 100 & \\
\hline 7 & 63 & 87. & & 1 & 9.1 & 0 & & 0 & \\
\hline
\end{tabular}


Continued

\begin{tabular}{cccccc}
\hline & \multicolumn{5}{c}{ How to present } \\
\multirow{2}{*}{$\begin{array}{c}\text { Apgar score in } \\
\text { the }^{\text {sst }} \text { minute }\end{array}$} & \multicolumn{4}{c}{ Full seat } & \multicolumn{2}{c}{ Unseating seat } & Statistical test \\
\cline { 2 - 5 } & Eff & $\%$ & Eff & $\%$ & \\
\hline 0 & 0 & 0 & 0 & 0 & - \\
$1-3$ & 2 & 5.6 & 2 & 2.4 & P-0.73 \\
$4-6$ & 9 & 25 & 13 & 15.5 & P-0.21 \\
7 & 25 & 69.4 & 69 & 82.1 & P-0.96 \\
\hline
\end{tabular}

Table 7. The frequency of home birth 2018-2019 at Kayes Hospital, Mali.

\begin{tabular}{ccc}
\hline Authors & staff & $\%$ \\
\hline Macombou P. Congo 2002 [6] & 345 & $4.7 \%$ \\
Touré M. Mali 2006 [7] & 105 & $2.1 \%$ \\
Hannah M E. Hannha W J. Canada 2000 [8] & - & $3 \%$ \\
Our Mali 2018 study & 120 & $3.14 \%$ \\
\hline
\end{tabular}

years respectively. We did not find a statistically significant correlation between age and seat presentation in this study P-0.05; on the other hand Dicko B. [9] in common V/Bamako in 2001 found that relative young age is a factor of poor fetal prognosis with a $\mathrm{p}-0.031$. The female population of Mali is predominantly made up of housewives. Thus we noted $84.2 \%$ of housewives among cases and 87.9\% among controls without statistically significant difference P-0.55. Most studies in Mali report markedly high rates of housewives So: Dicko B. [9] in 2001, Koné M. [2] in 2004, and Touré M. [7] in 2008 in Mali (Bamako) reported $91.3 \%, 71.43 \%$, and $90.5 \%$ in their respective studies. These are most often outof-school pregnant women, so they are very reluctant to understand the risks associated with this type of situation during pregnancy. The problem: in this study, the frequency of seat presentation decreases with parity. Thus we noted $39.2 \%$ of primiparous, $30.8 \%$ of paucipares among cases against $49.1 \%$ and $26.3 \%$ among the witnesses P-0.05. Other authors such as Koné M. [2] and Touré M. [7] Mali (Bamako) reported 33.6\% and 38.1\% primiparous with $37.83 \%$ and $21.9 \%$ paucipares. Our high rate of priparousness could be explained by the precocity of sexual intercourse (early marriage i.e. before the age of 18). Multipares and large multipares accounted for only $14.2 \%$ and $15.8 \%$ respectively in cases; statistically significant difference with their witnesses. Indeed, the accommodation disorder in the multipare due to the loosening of the uterine walls explains the occurrence of the presentations of the seat in the latter [2]. Surgical antecedents: a scary uterus always presents a risk of dehiscence during pregnancy or childbirth. In the case of the presentation of the seat, the history of uterine surgery is important to take into account as it may indicate a caesarean section from the outset. $15 \%$ of our cases had a history of caesarean section compared to $13.3 \%$ of P- 0.66 controls. Rates close to ours have been reported by 
Koné M. [2] and Dicko B. [9] 10.92\% and 11\% respectively. The history of caesarean section was found associated with brecover delivery in $4.8 \%$ and $7.4 \%$ of cases respectively in the Touré M. [7] studies in Mali and Farsi I F. [10] in Senegal. We found in this study $1.7 \%$ of cases of myomectomy.

Pregnancy follow-up: $9.2 \%$ of cases did not have any prenatal follow-up. This rate is close to that of the controls without a statistically significant difference (p-0.47). This rate is close to that of Manefoue HM. [13] 9.4\% at the G-spot CHU in 2008. Other authors like Brahim O. [14] in Tunisia; and Farsi I L. [10] in Senegal reported $35 \%$ and $34.1 \%$, respectively. One of the goals of prenatal consultation in the last month of pregnancy is to determine the prognosis of delivery. Most of the gestantes collected in this study did not benefit from this assessment either because of the poor quality of NPCs or because of the lack of prenatal follow-up. These are pregnant women whose prognosis of delivery has been assessed in the labour room sometimes in emergency situations. $20.8 \%$ of our cases were evacuated from other socio-health structures compared to $5 \%$ of the witnesses. These are the parturients who were first received in other structures and then evacuated because of abnormalities related to the evolution of the labour. Clinical examen: taille of the parturient, and obstetric assessment of size is important as soon as the gestant is admitted to the work room. $3.3 \%$ of our cases were less than $150 \mathrm{~cm}$ in size. This rate is close to that of witnesses (5\%) without a statistically significant difference (P-0.46). The size of $150 \mathrm{~cm}$ was associated with the presentation of the seat in $2.52 \%, 5.2 \% 7.6 \%$ respectively in [2] [7]. The average size of our cases was $163 \mathrm{~cm}$. Other authors like Farsi IF. [10] in Senegal and Rosenau L. [12] in France reported average sizes $163 \mathrm{~cm}$ and $162 \mathrm{~cm}$ respectively. Fetal cardiac cardiac rhythm: The assessment of the routine fetal heart rate at admission was done exclusively to Pinard's stethoscope. In this study, we found a frequency of bradycardia in cases: 5\%. Koné M. [2] reported in 2005 to Gabriel Touré $17.6 \%$ bradycardia. Our low rate could be explained by the absence of fairly sensitive equipment (cardiotocograph) in our service. Some factors may have contributed to altering the heart rate of the fetus in our study. These are: delays in the decision-making of the evacuation, the mode of evacuation, dynamic dystocies (15\%), mechanical dystocies (11\%), cord procidence (1.7\%). Fetal resentation: $30 \%$ of fetuses in admission cases had a full-seat presentation versus $70 \%$ of mode counted with a statistically significant difference of p-0.0000. Authors [2] [7] reported respectively 59.4\%, 54.6\%, and $51.4 \%$ full seat against $40.6 \%, 45.4 \%$ and $48.6 \%$ of decompeted fashion without having a statistically significant difference of $\mathrm{p}-0.05$. Primiparous with full seat presentation represented $44.4 \%$ versus $36.9 \%$ of the seat completed without a statistically significant difference ( $\mathrm{p}-0.43)$. The anterior left sacro iliac variety was most common with $85.8 \%$. In our cases, we found a statistically lower presentation engagement rate than their witnesses P-lt; 0.05 . This difference could be explained by the potentially dystopic nature of the labour in the presentation of the seat. 
Births: Several factors determined the pathway of delivery in this study. We found in this study a higher rate of caesarean section than the presentation of the summit $\mathrm{P}<0.05$; and cases were 6 times more likely to give birth by caesarean section than their witnesses (OR-5.6; IC: $(1.37$ - 3.82). Caesarean section was performed in $69.4 \%$ of the primigestes. These are caesarean sections performed in emergency $27 \%$ of cases. The main indication of caesarean section was the presentation of the seat in the primipare associated with other factors (acute fetal suffering, large fetus in presentation of the seat, elderly primipare and abnormality of the pelvis) (Table 8).

Overall, they are higher in developed countries ranging from $44.4 \%$ to $90 \%$. [15] [16].

This variation could be explained by the diversity of the means of prenatal and per partum surveillance that allow us to properly evaluate all the prognostic factors of childbirth in order to determine the ideal route, but also by the principle adopted by some schools (systematic caesarean section in all primipares with presentation of the seat). The obstetric manoeuvres used were dominated by those of Bracht 60\%, Mauriceau 9.2\%, and Lovset $0.8 \%$. Vermelin's method was not practiced in our series. Expulsion during vaginal deliveries is less than or equal to 45 minutes in most cases (90\%), compared to $93.75 \%$ of controls without a statistically significant difference of p-0.20. However, $10 \%$ of the cases had a deportation period of 45 minutes. These expulsion dystocies could be explained on the one hand by maternal exhaustion and on the other hand by dynamic dystocies requiring an infusion of oxytocin.

\subsection{The Pronostic}

\section{The maternal pronostic}

In the literature several types of maternal complications have been described [7]. In this study, several types of maternal complications were found. These complications depend on the factors that are either related to the pregnancy itself (follow-up), or the mode of delivery, or both. Thus the most frequently encountered

Table 8. Frequency of Caesarean section in the literature.

\begin{tabular}{|c|c|c|c|c|}
\hline continent & Authors & country & Frequency & Year \\
\hline & Farsi I F. [10] & Senegal & $32 \%$ & 1997 \\
\hline & Dicko B. [9] & Mali & $30 \%$ & 2001 \\
\hline & ILesanmi O A. [15] & Nigeria & $15 \%$ & 1996 \\
\hline & Our study & Mali & $30 \%$ & 2009 \\
\hline \multirow[t]{3}{*}{ Europe } & Denis A. [16] & France & $47.9 \%$ & 1990 \\
\hline & Saunders N J. & England & $90 \%$ & 1996 \\
\hline & Koo M R. & Netherlands & $44.4 \%$ & 1998 \\
\hline \multirow[t]{2}{*}{ USA } & Laros & USA & $82 \%$ & 1995 \\
\hline & Schiff E. & USA & $61.4 \%$ & 1996 \\
\hline
\end{tabular}


morbid complications were tears of the soft parts (15 cases or 12.5\%) and parietal suppuration ( 1 case or $0.8 \%$ ). We did not record any maternal deaths. Parietal suppuration, recorded in our study, was observed only in an evacuated parturient; it was not related to the presentation of the seat itself but is a morbid complication sometimes encountered after a caesarean section. If the maternal prognosis is generally good in delivery in the case of the presentation of the seat, the increase in the frequency of caesarean section is a factor to be taken into account.

\section{Fetal pronostic}

Acute fetal suffering was the main fetal complication found by most of the perpetrators. In our study, the frequency of acute fetal suffering in cases was statistically higher than that of our controls $\mathrm{P}<0.05$; but without any statistical difference with those of the other authors [2] [7] P-0.05. We found a case of dislocation of the shoulder. Several factors contributed to the alteration of the fetal prognosis during brecit birth. The route of delivery in the event of the presentation of the seat can be an important morbid factor especially if all the conditions of acceptance of the seat are not respected. We found an alteration in Apgar's score regardless of the route of delivery in our study, in cases compared to controls with an advantage in newborns born by caesarean section. We found a score of Apgar 7 at the fifth minute with no statistical difference between newborns born by caesarean section and those born by the lower route P-0.05. The benefit of caesarean section over vaginal delivery in children identified in our study is noted in the Canadian, British and American $\geq$ literature [2]. Hannah-Hannah [8] reported $0.4 \%$ fetal mortality in caesarean delivery compared to $5.7 \%$ after vaginal delivery. These rates are almost better at our $2.8 \%$ and $3.6 \%$. The fetal prognosis in our study was less good in the case of a full seat than in the case of a full seat because of the frequency of full seat abnormalities. 14\% of newborns in full seat presentation had an Apgar score of less than 7 in the 5th minute compared to $3.6 \%$ of newborns presenting the decomplete seat p-0.09. Our results are lower than those found by Dicko B. [9] and Koné M. [2] who rated $36.5 \%$ against $22 \%$ and $33.84 \%$ against $12 \%$ respectively. The fetal prognosis is inversely proportional to the length of expulsion. Indeed Apgar's scores in the 1st and 5th minutes were bad when the expulsion time is more than $45 \mathrm{mi}$ nutes. This would be explained by the fact that in the case of prolonged expulsion, especially if improper obstetric maneuvers are associated, hypoxia develops which results in the alteration of Apgar's score.

\section{Authors' Contributions}

All the authors participated in the writing of the manuscript. They all approve the final version of the manuscript.

\section{Ethics Authorisation}

The ethics committee's authorization was found prior to the start of the study. 


\section{Conflicts of Interest}

The authors state that they have no conflict of interest in this work.

\section{References}

[1] Robert, M., Jean, L. and Jean, M. (1995) Accurate Obstetrics. Introducing the Seat. 6th Edition, Masson, Paris, 618.

[2] Koné, M. (2005) Accouchement in Presentation by Fetal and Maternal Prognostic Seat in the Obstetric Gynecology Department of the Gabriel Touré Hospital. Med's Thesis, Bamako, No. 359.

[3] Wright, R.C. (1959) Reduction of Perinatal Mortality and Morbidity in Breech Delivery through Routine Use of Caesarean Section. Obstetrics \& Gynecology, 14, 758 763.

[4] Dufour, P. (2001) Introducing the Siege: The Last Day of the Low Track? Gynécologie Obstétrique \& Fertilité, 29, 337-338. https://doi.org/10.1016/S1297-9589(01)00142-4

[5] Raudrant, D., Vaudoyer, F. and Golfier, F. (2001) Champion F. Low Track or Caesarean Section? The Presentation of the Term Seat: The Arguments for the Cesarean Section in Principle. Gynécologie Obstétrique \& Fertilité, 29, 729-732.

[6] Macombou, P., Buambo, B., et al. (2006) Accouchement in Presentation of the Siege at the Brazzaville University Hospital. Black African Medicine, 53, 287-292.

[7] Touré, M. (2008) Accouchement in Presentation of the Seat at the csref C VI Fetal and Maternal Prognosis. Thesis Med., Bamako, Number 502.

[8] Hannah, M.E., Hannah, W.J., Hewson, S.A., Hodnett, E.D. and Saigal, S. (2000) Vaginal Presentation Delivery: The End of an Era. The Lancet, 356, 1357-1383. https://doi.org/10.1016/S0140-6736(00)02840-3

[9] Dicko, B. (2001) Siege Delivery, Fetal Prognosis for 103 Cases. Thesis Med., Bamako, Number 67.

[10] Farsi, I.F. (1997) Epidemiology of Childbirth in Presentation of the Seat and Early Neonatal Follow-Up in a Reference Maternity Hospital in Black Africa: Prospective Study in the Gynecology and Obstetrics Department of the Dakar University Hospital. Thesis Med., Dakar, It's 146.

[11] Erkaya, S., Tuncer, A., Kutlar, I., Onat, N. and Ercakmak, S. (1997) Outcome of 1040 Consecutive Breech Deliveries Clinical Experience of Maternity Hospital in Turkey. International Journal of Gynecology \& Obstetrics, 59, 115-118. https://doi.org/10.1016/S0020-7292(97)00197-5

[12] Rosenau, L., Grosieux, P., Denis, A., Lahlou, N. and Fournis, H. (1990) Facteurs pronostiques de l'accouchement en présentation du siège à propos de 357 grossesses monofoetales à terme. French Journal of Obstetricgynecology, 85, 271-281.

[13] Manefoue, H.M. (2008) Accouchement et présentation du siège à propos de 96 cas. Thèse de Med Bamako.

[14] Brahim, O., Rachdi, R., Fekih, M.A., Mouelhi, C. and Messaoud, L. (1993) Fetal Prognosis of Brecit Birth: Statistical Study of 543 Observations. French Journal of Obstetricgynecology, 884, 249-252.

[15] St. Saunders, N.J. (1996) Controversies: The Mature Breech Should Be Delivered by Elective Cesarean Section. Journal of Perinatal Medicine, 24, 545-551.

[16] Koo, M.R., Dekker, G.A. and Van Geizn, H.P. (1998) Perinatal Outcome of Singleton Term Breech Deliveries. European Journal of Obstetrics \& Gynecology and Reproductive Biology, 78, 19-24. https://doi.org/10.1016/s0301-2115(97)00278-9 